For 20 years the Nova Scotia government, through the Department of Environment, has run a successful Youth Conservation Corps that teams up Nova Scotia youth between the ages of 17-24 with community conservation projects. In 2010 the Department of Health Promotion and Protection will create a pilot Health Promotion Youth Corps modelled on the Youth Conservation Corps. The objective is to engage youth in health promotion policy and programming and provide young people with meaningful work experience. In its pilot year the focus will be on injury. The goal is to run and evaluate community-based projects related to road safety, youth violence, sexual assault, sports injury and self-harm. Each year the Youth Conservation Corps hires 50 youth to work on 25 projects across Nova Scotia. During the Health Promotion Youth Corps pilot 10 students will be hired to work on five projects.

\title{
0820 PILOTING A HEALTH PROMOTION YOUTH CORPS
}

M Green*, J Young, L Tobin Correspondence: Department of Health Promotion and Protection, 1601 Lower Water Street 5th Floor Halifax, Nova Scotia B3H 4J7, Canada 